\title{
Hand Assisted Laparoscopic Appendicectomy (HALA): A Safe Alternative Minimal Access Technique
}

\author{
${ }^{1}$ Aswini Kumar Misro, ${ }^{2}$ Radhika Mishra, ${ }^{3} \mathrm{M}$ L Shrestha \\ ${ }^{1}$ Assistant Professor, Department of Surgery, Lumbini Medical College and Research Center, Pravas, Tansen, Palpa, Nepal. \\ ${ }^{2}$ Medical Officer, Department of Surgery, Lumbini Medical College and Research Center, Pravas, Tansen, Palpa, Nepal. \\ ${ }^{3}$ Professor and Department Head, Department of Surgery, Lumbini Medical College and Research Center, Pravas, Tansen, \\ Palpa, Nepal.
}

Correspondence: Aswini Kumar Misro, Assistant Professor, Department of Surgery, Lumbini Medical College and Research Center, Pravas, Tansen, Palpa, Nepal. E-mail: aswini_mishra2@ rediffmail.com

\begin{abstract}
Introduction: Appendicectomy is a commonly performed surgical procedure. Conventional open appendicectomy is sometimes met with difficulties, particularly when the appendix is malpositioned, in obese patients and patients having peritonitis. On the other hand, laparoscopic appendicectomy conferring several advantages over the open technique is time consuming and requires complex maneuvers like intra and extracorporeal knotting. Understanding the advantages and disadvantages of the above two techniques, we have been using a combination of both which we will be terming as 口Hand Assisted Laparoscopic Appendicectomy (HALA)!.

Material and methods: 83 cases were subjected to appendicectomy using the mentioned technique both for acute and recurrent cases. Patients having gangrenous appendicitis or with necrotic and friable appendix were excluded from the study.

Observations and results: The results are as follows:

1. Duration of hospital stay: 2.4 days

2. Wound infection: $5 / 83$

3. Duration of follow-up: till 1 month postoperative.

4. Paralytic ileus:3/83

5. Operating time (mean): 30 minutes.

Conclusion: Hand assisted laparoscopic appendicectomy (HALA) is a safe alternative technique providing all advantages of minimal access surgery while reducing the complexities associated with it.
\end{abstract}

\section{INTRODUCTION}

Appendicectomy is a commonly performed surgical procedure. Conventional open appendicectomy is sometimes met with difficulties, particularly when the appendix is malpositioned, in obese patients and in patients having peritonitis. The above difficulties, mandates extension of incision many a times leading to increased operating time, pain and hospital stay and compounds other problems related to large incision.

On the other hand, Laparoscopic appendicectomy confers the advantage of better pain management, lesser wound infection, and faster recovery to normal. ${ }^{1}$ Moreover, it gives the opportunity for performing diagnostic laparoscopy, particularly in the women of child bearing age group. Lastly, it lowers the risk of adhesions, infection, dehiscence, and herniation. ${ }^{2}$ However it is time consuming and requires complex measures like intra and extracorporeal knotting.

Understanding the advantages and disadvantages of the above two techniques we have been using a combination of both which we will be terming as 'Hand Assisted Laparoscopic Appendicectomy(HALA)'.

In summary, 'Hand Assisted Laparoscopic Appendicectomy' means performing diagnostic laparoscopy, locating the appendix and delivering it out through the port and performing appendectomy in a way similar to the open technique.

\section{PATIENT AND METHOD}

An optical port, $5 \mathrm{~mm}$ or $11 \mathrm{~mm}$ is inserted in the supra umbilical region using open technique through the umbilical cicatrix (Fig. 1). After creating pneumoperitoneum, diagnostic laparoscopy is done to firstly, rule out any intra-abdominal injury, secondly to evaluate the cause of abdominal pain and lastly to localize the base of the appendix. Once the base is localized, a $5 \mathrm{~mm}$ or $10 \mathrm{~mm}$ port is inserted exactly above the base of the appendix. Appendix is delivered out of the later port using a Babcock (endoscopic) or atraumatic grasper (Fig. 2). If the appendix is located in the retrocecal position with lots of peri appendiceal adhesions, an additional port is inserted in the right upper quadrant. This helps in adhesionolysis, bipolar coagulation of mesoappendix if required and diagnostic laparoscopy (running the terminal ileum). In cosmetically conscious patients, this optional port can be inserted in suprapubic area as well. The rest of the procedure is conducted 


\section{Author pl. provide Figure 1}

\section{Author pl. provide Figure 3}

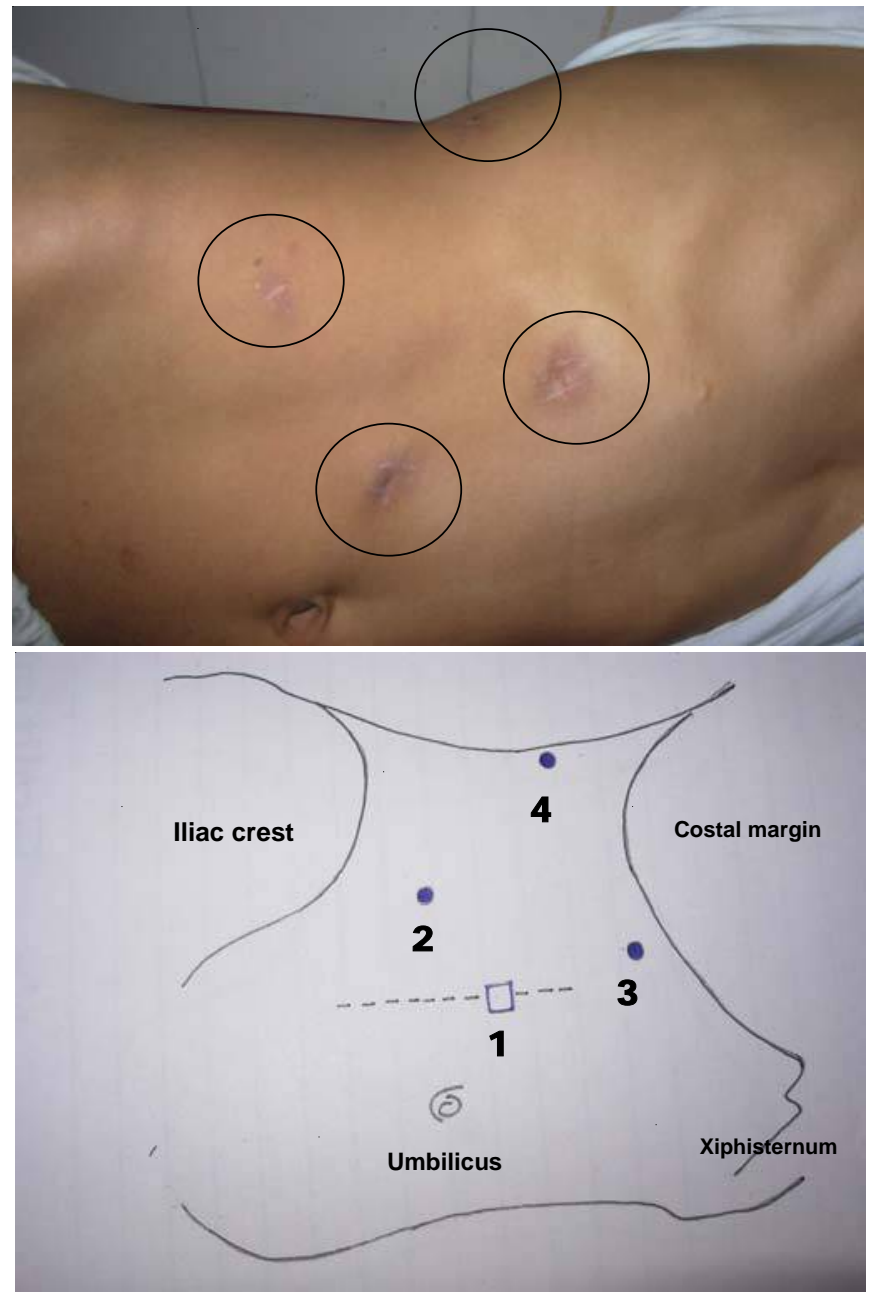

Fig. 2: Port sites for right transperitoneal pyeloplasty

(1) $\square$ Laparoscope pararectally above unbilicus

(2) $\square$ Surgeon!s left hand at mid spino umbilical line

(3) $\square$ Surgeon!s right hand subcostally

(4) $\square$ Assistant, mid axillary line

\section{Author pl. provide Figure 4}

similar to the open technique that is mesoappendix is clamped, cut and ligated, and the base of the appendix is transfixed (Figs 3 and 4). After distal ligation, the appendix is cut in-between and removed. The mucosa of the appendiceal stump is cauterized. Hemostasis is confirmed. Appendiceal stump is pushed inside and a $10 \mathrm{~mm}$ port is reinserted, to examine the terminal ileum, colon, female pelvic organs and mesentery and lastly, to take biopsy, if necessary. In case of difficulty in delivering out the appendix through the port (as in Fig. 2) due to kinking of the appendix, a serial ligation of the mesoappendix has to be deployed. This helps in delivery of the appendix bit by bit. Thorough wound toileting/irrigation is done, in case of acute appendicitis, at the end of the procedure.

Eighty-three cases were subjected to appendicectomy using the mentioned technique. This was used for acute and recurrent 
cases. Patients having gangrenous appendicitis or necrotic and friable appendix were not subjected to the above technique.

\section{OBSERVATION AND RESULTS}

The results are as follows:

1. Duration of hospital stay: 2.4 days

2. Wound infection: $5 / 83$

3. Duration of follow-up: till 1 month postoperative.

4. Paralytic ileus: $3 / 83$

5. Operating time (mean): 30 minutes.

\section{CONCLUSION}

Hand assisted laparoscopic appendicectomy (HALA) is a safe alternative technique providing all advantages of minimal access surgery while reducing the complexities associated with it.

\section{REFERENCES}

1. Garbutt JM, Soper NJ, Shannon WD, Botero A, Littenberg B. Meta-analysis of randomized controlled trials comparing laparoscopic and open appendectomy. Surg Laparosc Endosc 1999;9:17-26.

2. Kum CK, Ngoi SS, Goh PMY, Tekant Y, Isaac JR. Randomized controlled trial comparing laparoscopic and open appendectomy. Br J Surg 1993;80:1599-1600. 